\title{
Experimental Study on the Mechanical Properties and Damage Evolution of Hollow Cylindrical Granite Specimens Subjected to Cyclic Coupled Static-Dynamic Loads
}

\author{
Yongming Xue,, ${ }^{1,2}$ Bing Dai, ${ }^{1,2}$ Ying Chen $\mathbb{D}^{1,2}$ Lei Zhang, ${ }^{1,2}$ Guicheng He, \\ and Zhijun Zhang $\mathbb{1}^{1,2}$ \\ ${ }^{1}$ School of Resources Environment and Safety Engineering, University of South China, Hengyang, China \\ ${ }^{2}$ Hunan Province Engineering Technology, Research Center for Disaster Prediction and Control on Mining Geotechnical Engineering, \\ 421001 Hengyang, China
}

Correspondence should be addressed to Ying Chen; csu_chenying@csu.edu.cn

Received 13 July 2020; Revised 19 August 2020; Accepted 26 August 2020; Published 22 September 2020

Academic Editor: Zhengyang Song

Copyright ( 2020 Yongming Xue et al. This is an open access article distributed under the Creative Commons Attribution License, which permits unrestricted use, distribution, and reproduction in any medium, provided the original work is properly cited.

\begin{abstract}
To study the characteristics of roadway surrounding rock damage caused by frequent disturbances under different static stress conditions, cyclic impact tests on granite with vertical holes under different axial prestress conditions were performed by a modified split Hopkinson pressure bar test, and the damage of the specimens was recorded with a high-speed camera process. The test results show that under the same air pressure cyclic impact, the rock specimens mainly undergo the compactionfatigue-failure transition. As the axial prestress increases, the compaction-fatigue phase gradually weakens, and the dynamic compressive strength decreases. When the axial prestress is $42 \%$ of the UCS and $62 \%$ of the UCS, the rock specimen shows a certain "strengthening" effect during the initial cyclic impact stage. During the failure of the rock specimens, the axial prestressing effect limited the initiation of some transverse cracks, and a mixed tensile-shear failure mode appeared. The rock specimens with an axial prestress of $62 \%$ of the UCS showed energy release during cyclic impact. To some extent, the probability of "rock bursts" has been induced. Based on the one-dimensional stress wave theory, the damage variables of wave impedance during the cyclic impact loading of the rock with vertical holes are defined. It is found that when the rock specimen is in the stage of compaction and fatigue damage, the damage is small, and the damage is even reduced.
\end{abstract}

\section{Introduction}

As the main carrier of loads in underground engineering applications, the structure and structural stability of rock are closely related to engineering safety. In recent years, with the continuous lack of shallow resources and the need for economic development for various countries, an increasing number of underground spaces have been developed at greater depths, such as mining, highway tunnel construction, and roadway excavation engineering projects [1-3], which trigger the continuous change of the stress state of the deep surrounding rock. In the process of underground rock excavation, the surrounding rock structure will inevitably be subjected to ground stress and mechanical drilling and blasting. The common effect of frequent disturbance $[4,5]$ and various factors lead to deformation, failure, and instability of the rock mass structure, which leads to a series of engineering disasters, such as intensified instability of the roadway [6-8] and rock burst $[9,10]$. Therefore, one-dimensional dynamic static coupling can better reflect the actual stress state of roadway excavation. The study of the dynamic characteristics of the surrounding rock under dynamic and static coupling has important reference significance for the safe construction $[11,12]$, efficient operation [13], and long-term stability of underground rock engineering.

Therefore, domestic and foreign scholars have performed much research on the mechanical properties of rocks under coupled static-dynamic loads. Zhou et al. [14-18] used an improved Hopkinson pressure bar system to analyse the mechanical properties of rock under the combined action 
of one-dimensional dynamic and static combinations and tested dried sandstone and water-saturated sandstone with different axial prestresses to study the influence of water saturation on the dynamic characteristics of rock under static prestress. Wang et al. [19] carried out experimental studies on different axial pressures and different impact loads on red sandstone and analysed the effects of axial pressure and impact loads on their mechanical properties and energy loss. Gong et al. [20-22] studied the dynamic characteristics of sandstone under coupled static-dynamic loads. The study found that when sandstone is loaded and destroyed within a certain range of axial pressure ratios, as the incident energy increases, the sandstone successively undergoes the three stages of "absorbed energy-release energy-absorbed energy". The above studies are based on the experimental study of intact rock samples under impact loading and have obtained abundant research results. However, rock failure and instability usually begin with primitive defects such as rock cracks and holes $[23,24]$. At present, there are few studies on defective rocks under impact loading. Li et al. [25-27] performed a one-dimensional dynamic and static combination test on samples containing circular and elliptical holes and found that the size, shape, and location of the holes have a certain effect on the dynamic strength of the rock, and the existence of holes induces shear failure of rocks. Wang et al. [28] used Hopkinson rods and combined digital image correlation technology to carry out impact experiments on rock-like samples with an angle of $0^{\circ}$ to $90^{\circ}$ between the prefabrication and loading directions and analysed samples under conditions of multiple loading rates, single cracks, and multiple angles. Li et al. [29] tested granite with square and circular holes to test the instability failure characteristics and obtained the relaxation time $\mathrm{T} 2$ spectrum curve, nuclear magnetic porosity, and nuclear magnetic resonance images under nuclear magnetic resonance (NMR) tests. In summary, most of the previous studies utilized impact tests based on prefabricated lateral cavity rock samples perpendicular to the loading direction, and few studies have been conducted on vertical holes. In the actual underground tunnel excavation process, frequent dynamic disturbances generated by mechanical drilling and blasting in the form of stress waves act on the surrounding rock of the excavated tunnel, which has a greater impact on its stability, and the surrounding rock of the tunnel when subjected to dynamic load disturbances. The rock is subjected to static loads such as in situ stress and tectonic stress [30], as shown in Figure 1. Therefore, understanding the failure mechanism of roadway surrounding rock under cyclic impact loading and certain static stress conditions is the essential basic information and basis for scientifically evaluating the stability of surrounding rock during the excavation of underground roadways.

Thick wall cylinders are the preferred model for simulating underground tunnels, tunnels, mine shafts, and other structures [31]. To correctly understand the mechanical properties, energy, and damage evolution of surrounding rock under the coupling action of static stress and dynamic disturbance in an actual project, this paper selects a granite cylinder with inner and outer diameters of $5 \mathrm{~mm}$ and $25 \mathrm{~mm}$, respectively, and uses the modified Hopkinson bar

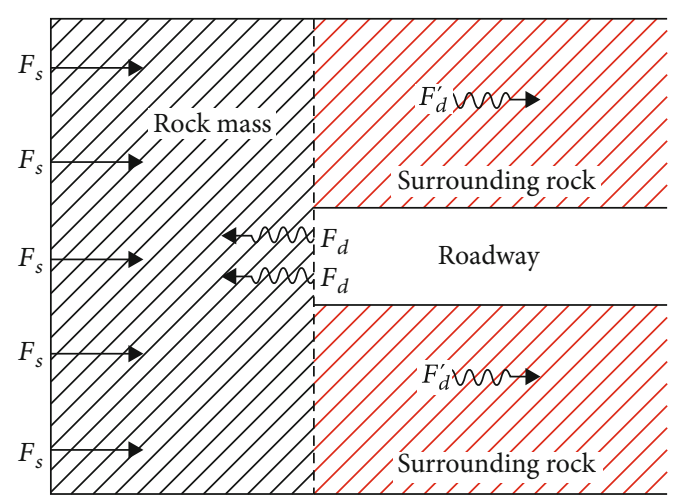

FIgURE 1: Schematic diagram of the surrounding rock forces during tunnel excavation $\left(F_{s}\right.$ : static stress, $F_{d}$ : dynamic load, and $F_{d}^{\prime}$ : dynamic disturbance).

system of Central South University to carry out cyclic impact tests on the granite under the same air pressure and different axial prestresses and uses high-speed photography. The image machine records the failure process of the specimen and analyses the mechanical behaviour, failure mode, energy evolution, and damage characteristics of the specimen under dynamic static coupling action.

\section{Test Methods and Specimen Preparation}

2.1. Specimen Preparation and Test System. The test material is granite with relatively good integrity and uniformity, processed into a $50 \mathrm{~mm} \times 100 \mathrm{~mm}$ cylindrical rock sample. Then, a vertical hole with a diameter of $10 \mathrm{~mm}$ is prefabricated in the centre of the circular cross-section, and the two cross sections at both ends of the sample, which exhibit nonparallelism and nonverticality, are less than $0.02 \mathrm{~mm}$, as shown in Figure 2. To reduce the discreteness of the rock samples, a rock acoustic wave parameter test system (HS-YS4A type) is used to test the $P$-wave velocity of the rock samples. The average density of the rock samples is $2.79 \times 10^{3} \mathrm{~kg} / \mathrm{m}^{3}$, the average $P$-wave velocity is $5345 \mathrm{~m} / \mathrm{s}$, and the average compressive strength is $140 \mathrm{MPa}$.

2.2. Testing Equipment. The test equipment uses the dynamic and static combined loading test system based on the SHPB device modified by Central South University. It consists of a punch device, an incident rod, a transmission rod, a buffer rod, and an axial compression device, as shown in Figure 3. The rods of the test system are made of $40 \mathrm{Cr}$ alloy steel with a diameter of $50 \mathrm{~mm}$. The longitudinal wave velocity is $5400 \mathrm{~m} / \mathrm{s}$, the density is $7810 \mathrm{~kg} / \mathrm{m}^{3}$, and the elastic modulus is $240 \mathrm{GPa}$. The data acquisition instrument and display equipment are a CS-1D super dynamic strain gauge and DL-750 oscilloscope, respectively. A spindle-shaped bullet is used in the launch cavity to eliminate wave oscillations and achieve stable half-sine wave loading to achieve a constant strain rate loading effect. To facilitate the observation of the microdestruction process of the test piece, a FASTCAM SA1.1 high-speed camera is used to synchronously record the crack propagation process of the test piece. The frame number of the high-speed camera is set to $43,200 \mathrm{fps}$ 

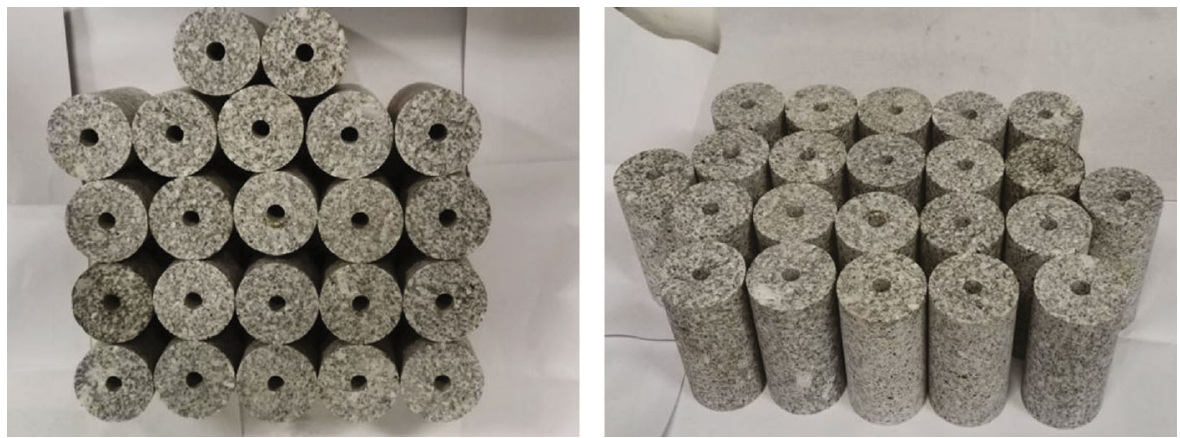

FIgURe 2: Rock test samples.

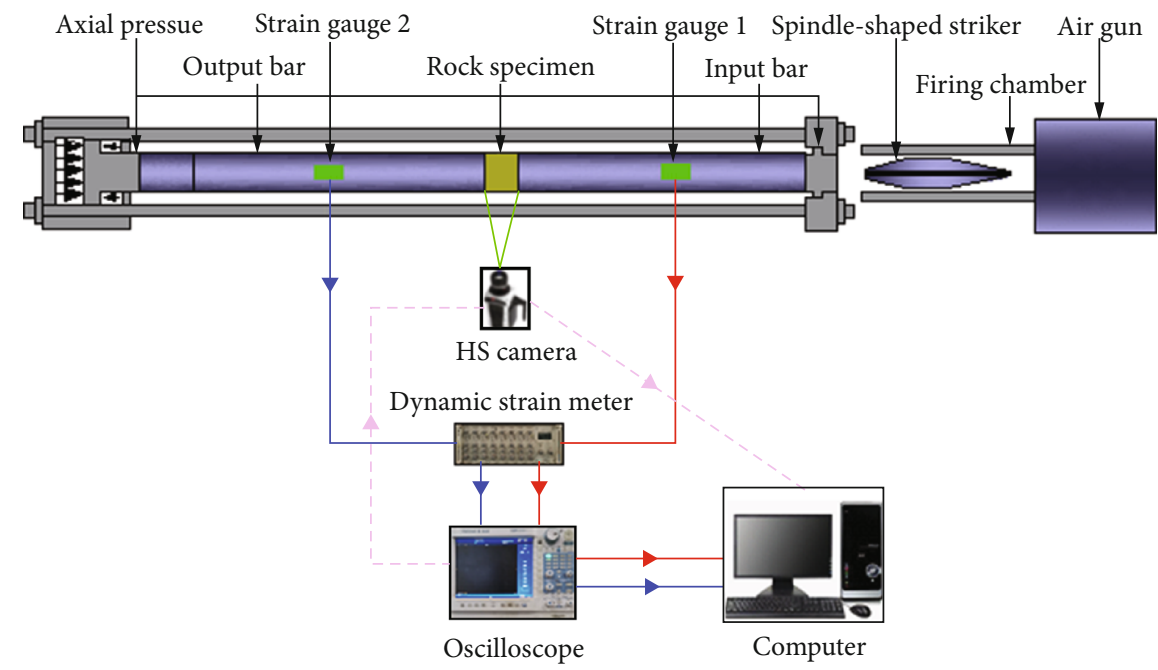

FIGURE 3: Rock dynamic and static combination based on the SHPB device.

and shot once at an interval of $23 \mu$ s. Figure 4 shows the dynamic and static combination loading schematic of the test piece.

\subsection{Test Plan}

2.3.1. Test Method. To study the impact mechanical properties, energy, and damage evolution law of granite with vertical holes under different prestressing effects, the axial prestressing load was set to $0.55 \mathrm{MPa}$ ( $42 \%$ of the UCS), $82 \mathrm{MPa}(62 \%$ of the UCS), and $110 \mathrm{MPa}$ in this experiment ( $83 \%$ of the UCS) to carry out cyclic impact loading. To ensure the reliability of the data, each group of data was tested for 3 samples. The test piece number was in the form of Z-0-1, where 0 and 1 represented the axial pressure of 0 and the test piece group number, and $\mathrm{A}, \mathrm{B}$, and $\mathrm{C}$ represented the prestress force of 55, 83, and $110 \mathrm{MPa}$, respectively. The test scheme is shown in Table 1.

2.3.2. Test Procedure. To test the effectiveness, before the start of the test, the incident rod and the transmission rod are closely pressed for empty punching, and the trend of the incident wave and the transmitted wave on the oscilloscope is observed to ensure whether the two rods are normally secured.
To achieve the purpose of cyclic impact of the rock sample under different prestressing effects and to avoid the rock sample being damaged, it is necessary to test the rock sample and finally set the impact pressure to $0.8 \mathrm{MPa}$.

During the test, lubricating oil should be applied between the incident rod and the transmission rod to reduce the end effect of the sample, the rock should be sandwiched between the incident rod and the transmission rod, and then the manual oil pump should be slowly prestressed to the set value. The strain gauge, oscilloscope, and high-speed camera are initiated to record data.

2.4. Test Principle. The SHPB system can simultaneously realize dynamic and static combined tests with an axial prestress of $0-200 \mathrm{MPa}$ and an impact dynamic load of 0 $500 \mathrm{MPa}$. The punch impacts the incident rod at a certain rate under the action of air pressure, and an incident stress wave is formed in the incident rod. When the incident stress wave is transmitted to the end face of the rock sample, transmission stress is formed on the end face of the rock sample due to the different wave impedances of the rock sample and the rod. The incident and transmitted waves can be measured from incident rod strain gauge 1 and transmitted rod strain gauge 2, respectively, as shown in Figure 2. Using the "three wave method" [32] to process the collected wave 


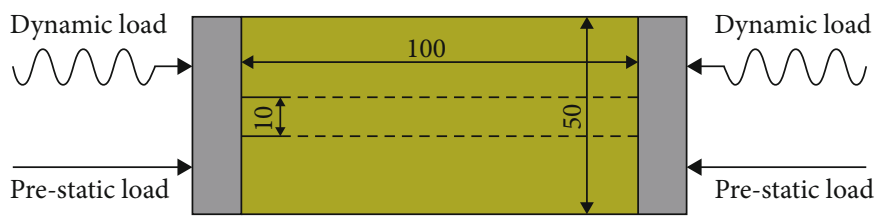

FIgURE 4: Schematic diagram of the combined dynamic and static loading of the test specimens.

TABLE 1: Basic physical parameters and test plan of the rock specimens.

\begin{tabular}{lcccc}
\hline $\begin{array}{l}\text { Rock } \\
\text { specimen } \\
\text { number }\end{array}$ & $\begin{array}{c}\text { Diameter } \\
(\mathrm{mm})\end{array}$ & $\begin{array}{c}\text { Height } \\
(\mathrm{mm})\end{array}$ & $\begin{array}{c}\text { Axial } \\
\text { prestress } \\
(\mathrm{MPa})\end{array}$ & $\begin{array}{c}\text { Impact air } \\
\text { pressure } \\
(\mathrm{MPa})\end{array}$ \\
\hline Z-0-1 & 50.2 & 99.81 & & \\
Z-0-2 & 49.98 & 100.21 & 0 & \\
Z-0-3 & 50.03 & 100.10 & & \\
Z-A-1 & 49.81 & 99.89 & & \\
Z-A-2 & 49.98 & 100.02 & 55 & \\
Z-A-3 & 50.12 & 99.89 & & \\
Z-B-1 & 49.63 & 100.12 & & \\
Z-B-2 & 49.95 & 99.98 & 83 & \\
Z-B-3 & 49.95 & 99.91 & & \\
Z-C-1 & 50.26 & 100.08 & & \\
Z-C-2 & 50.08 & 99.96 & 110 & \\
Z-C-3 & 49.89 & 100.18 & & \\
\hline
\end{tabular}

forms, we can obtain the changes in the strain, stress, and strain rate with time as follows:

$$
\begin{aligned}
\varepsilon(t) & =\frac{C_{e}}{L_{s}} \int_{0}^{t}\left[\varepsilon_{I}(t)-\varepsilon_{R}(t)-\varepsilon_{T}(t)\right] d t, \\
\sigma(t) & =\frac{E_{e} A_{e}}{2 A_{s}}\left[\varepsilon_{I}(t)+\varepsilon_{R}(t)+\varepsilon_{T}(t)\right] d t, \\
\dot{\varepsilon} & =\frac{C_{e}}{L_{s}}\left[\varepsilon_{I}(t)-\varepsilon_{R}(t)-\varepsilon_{T}(t)\right] d t .
\end{aligned}
$$

In the SHPB test, it is assumed that the energy loss generated by the end face of the specimen is negligible. The energy before the test is equal to the energy after the test. According to the law of the conservation of energy [32], the incident energy, reflection energy, transmitted energy, and formula for absorbed energy are as follows:

$$
\begin{aligned}
& W_{I}=\frac{A_{e} C_{e}}{E_{e}} \int_{0}^{t} \sigma_{I}^{2}(t) d t, \\
& W_{R}=\frac{A_{e} C_{e}}{E_{e}} \int_{0}^{t} \sigma_{R}^{2}(t) d t, \\
& W_{T}=\frac{A_{e} C_{e}}{E_{e}} \int_{0}^{t} \sigma_{T}^{2}(t) d t, \\
& W_{s}=W_{I}-W_{R}-W_{T},
\end{aligned}
$$

where $A_{e}$ and $A_{s}$ denote the cross-sectional area of the elastic rod and the sample, respectively; $E_{e}$ represents the elastic modulus of the elastic rod; $C_{e}$ and $L_{s}$ represent the longitudinal wave velocity of the elastic rod and the length of the sample; $\varepsilon_{I}(t), \varepsilon_{R}(t)$ and $\varepsilon_{T}(t)$ represent incident, reflected, and transmitted strain wave signals, respectively; $\varepsilon(t)$ and $\sigma(t)$ are the strain and stress, respectively; $W_{I}, W_{R}, W_{T}$, and $W_{S}$ are the incident energy, reflected energy, transmitted energy, and absorbed energy, respectively.

\section{Test Results and Discussion}

The posttest data are processed based on the three-wave method. Due to space limitations, some test specimens are selected for analysis in this article. The test results are shown in Table 2.

\subsection{Mechanical Behaviour of Granite under Dynamic and Static Coupling}

3.1.1. Dynamic Stress-Strain Curve. Figure 5 shows the stressstrain curve of a rock sample during cyclic impact under different axial prestressing forces. Figure 5 shows that the stressstrain curve can be roughly divided into a compaction stage, a crack propagation stage, and a postpeak unloading stage. In the crack growth stage, when a relatively smooth curve appears before the peak stress is approached, the stress growth is slow, and the strain growth rate is faster as the yield stage continues; when the strain increases to a certain level, the peak stress rapidly increases and is defined as the strengthening stage. As the axial prestress increases, the yield stage becomes less and less obvious. Before reaching the peak stress, the change trends of the stress-strain curves are similar, but there are obvious differences in the unloading phases after the peak. Before the failure of the rock sample, the maximum strain at the unloading stage after the peak increases first and then decreases with the decrease in the stress, showing a rebound phenomenon; when the rock sample is impacted and destroyed, the rebound phenomenon gradually disappears.

3.1.2. Effect of the Axial Prestress on the Peak Stress. In the process of cyclic impact loading under different axial prestresses, the peak stress and the number of cyclic impact changes are shown in Figure 6. As the number of cycles increases, the peak stresses of Z-0-1 and Z-C-1 continue to decrease, while the peak stresses of rock samples Z-A-3 and Z-B-2 have an increasing trend during the initial impact stage, and their peak stress performance thereafter gradually decreases. According to the analysis, in the initial impact stage of samples Z-A-3 and Z-B-2, internal microcracks are closed under the impact load, which means that the wave 
TABLE 2: Test results of the rock specimens.

\begin{tabular}{|c|c|c|c|c|c|c|}
\hline $\begin{array}{l}\text { Rock specimen } \\
\text { number }\end{array}$ & $\begin{array}{c}\text { Impact } \\
\text { sequence }\end{array}$ & $\begin{array}{c}\text { Peak stress } \\
(\mathrm{MPa})\end{array}$ & $\begin{array}{l}\text { Peak strain } \\
(\mathrm{mm})\end{array}$ & $\begin{array}{c}\text { Maximum strain } \\
(\mathrm{mm})\end{array}$ & $\begin{array}{c}\text { Average strain rate } \\
\left(\mathrm{s}^{-1}\right)\end{array}$ & $\begin{array}{c}\text { Absorbed energy } \\
(\mathrm{J})\end{array}$ \\
\hline \multirow{3}{*}{ Z-0-1 } & 1 & 148.84 & 0.0039 & 0.0040 & 34.74 & 2.77 \\
\hline & 2 & 144.70 & 0.0034 & 0.0035 & 35.10 & 10.64 \\
\hline & 3 & 118.62 & 0.0042 & 0.0043 & 38.78 & 14.43 \\
\hline \multirow{6}{*}{ Z-A-3 } & 1 & 118.20 & 0.0034 & 0.0034 & 34.62 & -25.03 \\
\hline & 2 & 121.45 & 0.0035 & 0.0035 & 35.99 & -12.27 \\
\hline & 3 & 138.33 & 0.0027 & 0.0028 & 30.73 & 1.14 \\
\hline & 4 & 132.89 & 0.0028 & 0.0028 & 29.31 & 2.42 \\
\hline & 5 & 131.08 & 0.0029 & 0.0031 & 32.16 & 7.88 \\
\hline & 6 & 97.97 & 0.0028 & 0.0044 & 41.67 & 28.48 \\
\hline \multirow{7}{*}{ Z-B-2 } & 1 & 106.01 & 0.0032 & 0.0033 & 27.43 & -39.23 \\
\hline & 2 & 109.27 & 0.0028 & 0.0030 & 29.27 & -30.46 \\
\hline & 3 & 124.45 & 0.0027 & 0.0030 & 27.04 & -42.09 \\
\hline & 4 & 109.57 & 0.0028 & 0.0031 & 28.69 & -44.10 \\
\hline & 5 & 109.27 & 0.0035 & 0.0037 & 33.57 & -37.96 \\
\hline & 6 & 100.09 & 0.0033 & 0.0039 & 34.07 & -16.52 \\
\hline & 7 & 61.42 & 0.0026 & 0.0081 & 41.22 & -7.95 \\
\hline \multirow{2}{*}{ Z-C-1 } & 1 & 101.93 & 0.0026 & 0.0029 & 25.01 & -18.92 \\
\hline & 2 & 99.60 & 0.0031 & 0.0034 & 30.60 & 8.79 \\
\hline
\end{tabular}

impedance of the rock sample increases and the peak stress increases [33]. In the subsequent impact process, the internal cracks of the rock samples gradually increase, the wave impedance of the samples gradually decreases, and the ability to resist external loads continues to weaken, which reflects the strength degradation characteristics of the rock sample during cyclic impact. However, due to the large axial prestress, Z-C-1 causes many internal microcracks, which greatly weakens the resistance of the rock sample to external loads. Under dynamic loading, the peak stress shows a decrease with an increase in the number of cycles.

Figure 6 can further illustrate the effect of the axial prestress on the peak stress of the rock samples under the same air pressure. It can be seen from Figure 6 that the dynamic peak strength of unstressed rock samples is higher than that of prestressed axial forces, and the dynamic peak strength decreases as the axial prestress increases. When the axial prestress is $42 \%$ of the UCS and $62 \%$ of the UCS, the number of impacts increases compared to the case without axial prestress, and when the axial prestress is $83 \%$ of the UCS, the number of impacts is reduced. From the above phenomenon, it can be determined that the axial prestress has a certain effect on the dynamic strength and stiffness of the material. These phenomena can be explained by different stress stages under uniaxial compression [14]. Generally, the behaviour of brittle rock can be divided into three stages during uniaxial compression: (I) elastic deformation stage: approximately $0-30 \%$ of the UCS; (II) crack steady propagation stage: approximately $30-70 \%$ of the UCS; and (III) unstable crack growth stage: approximately $70-100 \%$ of the UCS, as shown in Figure 7.

The axial prestress is in the stage of stable crack propagation, and activated cracks regenerated inside the rock sample.
When the peak strength of the dynamic load is lower than a certain value, during the initial cyclic impact of the rock sample, the damage caused by the dynamic load is generally lower than the crack closure amount, and the rock sample shows a compaction process [34]. When the axial prestress is $42 \%$ of the UCS and $62 \%$ of the UCS, the dynamic strength of the rock sample is lower than that without prestressing, indicating that the prestress has caused some damage to the rock sample, but due to the axial prestressing effect, the local damage has an impact on the specimen failure and has a strengthening effect on the rock material. Therefore, the stiffness is enhanced compared with the prestress. At an axial prestress of $83 \%$ of the UCS, the rock sample is in the stage of unstable crack propagation. The internal cracks greatly deteriorate the mechanical properties of the rock, showing its minimum dynamic strength and minimum number of impacts.

\subsubsection{Variation in the Average Strain Rate and Maximum} Strain. The average strain rate represents the amount of strain per unit time of the rock during a single impact [34]. Figures 8 and 9 show the relationship between the average strain rate and the maximum strain with the number of cycles when the rock samples are subjected to different axial prestresses. It can be seen that the average strain rate and the maximum strain increase as a whole. Z-0-1 shows a relatively large average strain rate and maximum strain during the first impact. According to the analysis, some initial cracks cannot be avoided inside the rock sample, and more stress may be generated around the hole wall during the impact due to the stress concentration. The crack shows a larger strain rate and maximum strain during the initial impact; the average strain rate and maximum strain of Z-A-3 during 

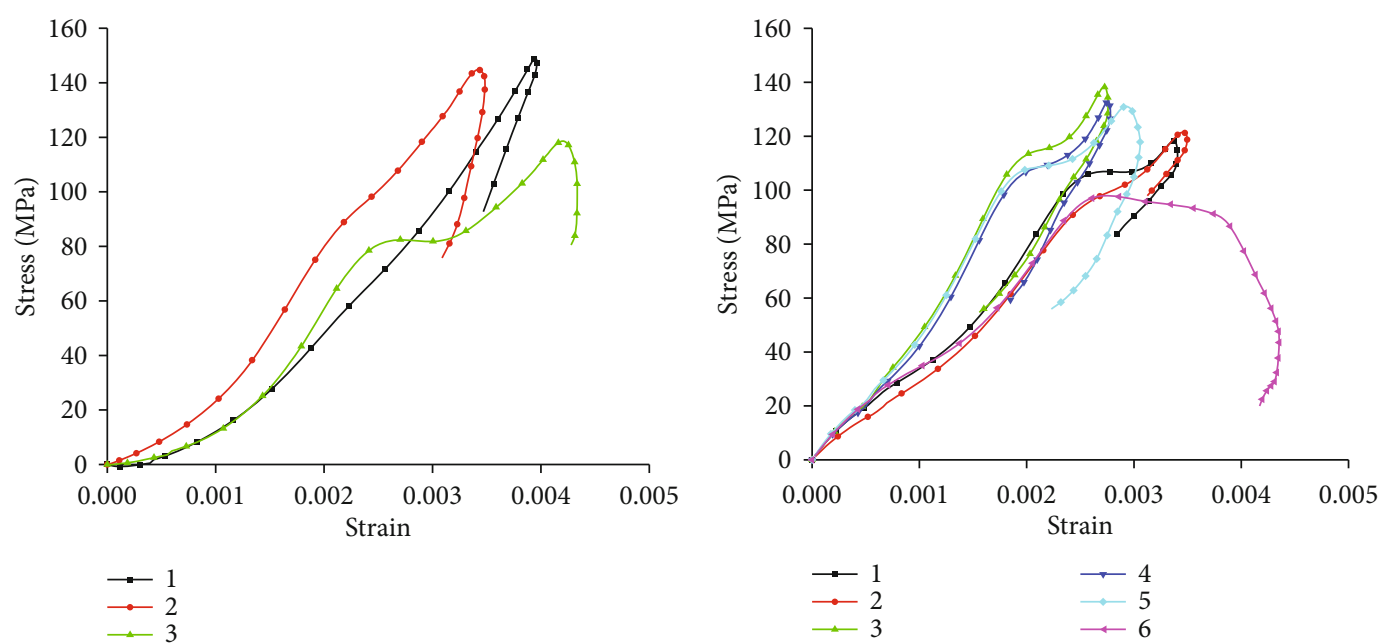

(a) Z-0-1

(b) Z-A-3

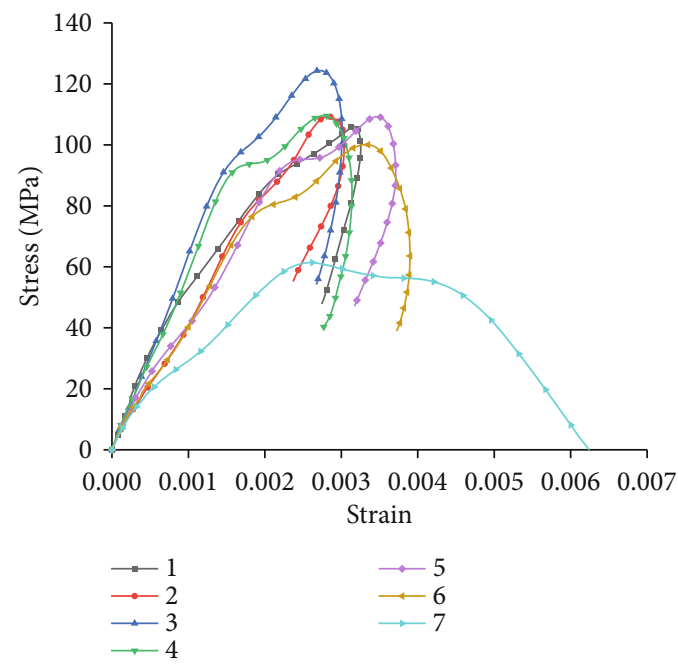

(c) Z-B-2

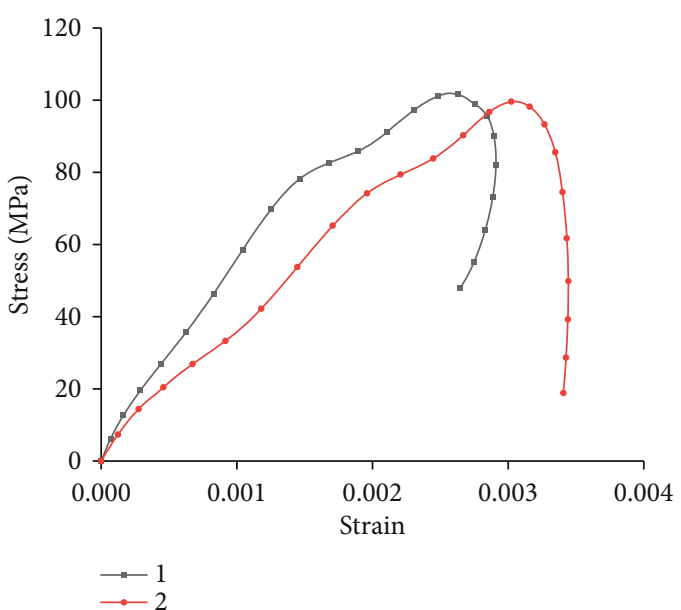

(d) Z-C-1

Figure 5: Dynamic stress-strain curve.

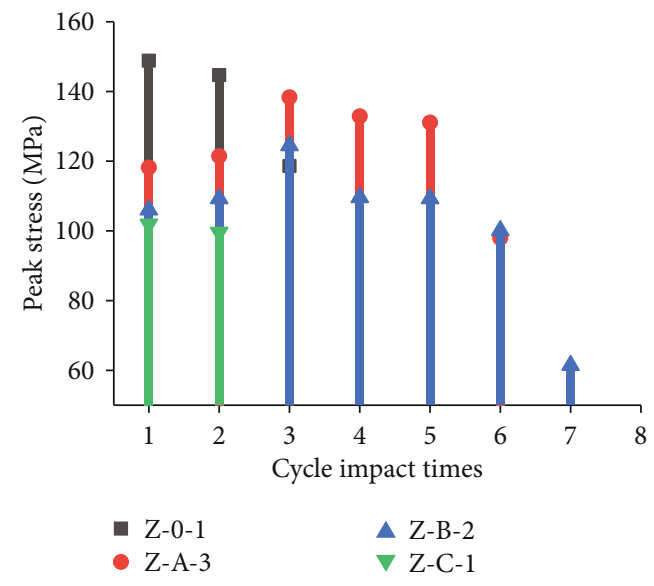

FIGURE 6: Relationship between the peak stress and cycle impact times. the first impact are lower than those of Z-0-1, which is due to the axial prestress. Effected by the initial crack closure, the first time the impact is initiated with the same air pressure, the crack closure amount is relatively small. In the same way, with the increase in the axial prestress, the internal crack closure of the rock samples increases, and the average strain rate and maximum strain of Z-B-2 and Z-C-1 are substantially reduced compared with Z-A-3 at the first impact. As the number of impacts accumulates, Z-A-3 and Z-B-2 show an average strain rate and a maximum strain that first decrease and then increase, and the strain of Z-C-1 increases as a whole. The analysis shows that during the initial impact of Z-A-3, the crack closure amount of the rock sample is larger than the crack initiation amount, showing a decreasing trend of the average strain rate and that the maximum strain decreases; with the increase in the number of cycles, the rock sample is in the third stage. During the fifth impact process, the average strain rate and the maximum strain change range decrease, indicating that the microcracks at this stage of the rock specimens develop slowly. The analysis indicates that 


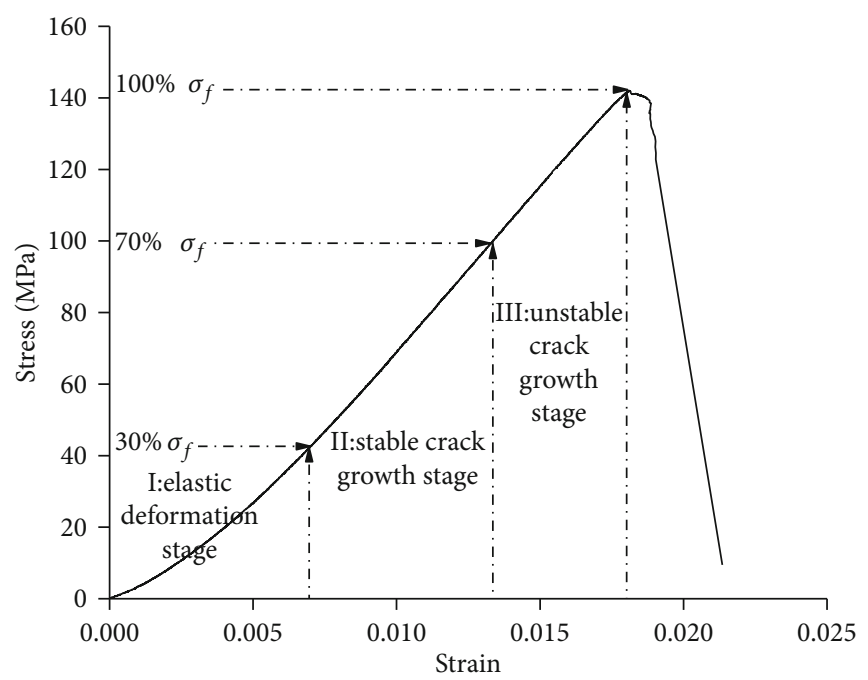

FiguRE 7: Uniaxial stress-strain curve.

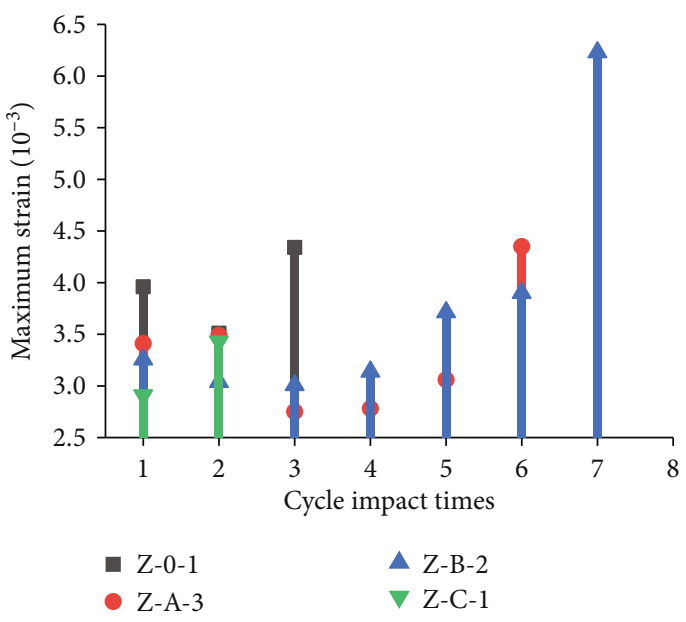

FIGURE 8: Relationship between the maximum strain and cycle impact times.

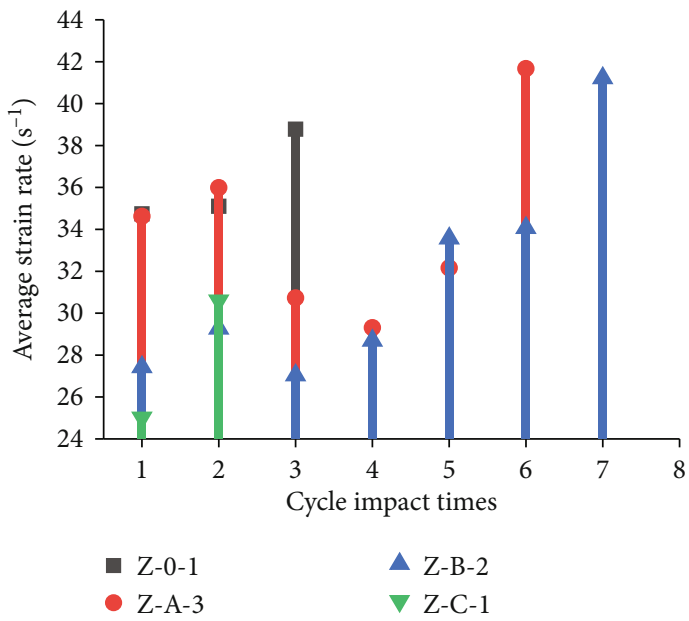

FIGURE 9: Relationship between the average strain rate and number of cycles. the rock specimens transition from the initial compaction stage to the fatigue damage stage and finally collapse. At this time, cracks in the rock samples rapidly expand, and the average strain rate and maximum strain increase substantially. During the initial impact of Z-B-2, the average strain rate and the maximum strain change are small, and the crack growth rate of the rock sample is very slow or does not expand. The average strain rate and the maximum value during the third impact should reach a minimum, indicating that the rock sample is in the first three stages. The crack closure stage is at the initial stage of fatigue damage; when the rock sample is impacted for the fifth time, the average strain rate and maximum strain of the rock sample increase substantially, indicating that the crack growth speed of the rock sample accelerates, which represents the transition from the fatigue damage stage to the failure stage. The Z-C-1 strain rate and average strain rate increase with increasing number of cycles. According to the analysis, a large number of microcracks appear in the sample due to the prestressing effect. When the impact load is applied, the initiation cracks are promoted to develop into the macrocrack direction. No compaction stage or fatigue damage stage is shown. In summary, when the axial prestress is low, the rock sample undergoes three stages during the cyclic impact process: the compaction phase, fatigue damage phase, and failure phase; as the prestress increases, the rock sample compaction phase weakens. There are two phases: the fatigue damage phase and failure phase; when the prestress is greater than a certain value, the rock sample only shows the failure phase.

3.1.4. Effect of Different Prestressing Effects on the Dynamic Deformation Modulus. Figure 10 shows the relationship between the dynamic deformation modulus of the rock sample and the number of cycles during different axial prestressed cyclic impacts. The dynamic deformation modulus reflects the resistance of the rock to deformation. Because the dynamic stress-strain curve has no obvious straight line segment, to better reflect the rock's resistance to deformation during impact, reduce errors, and reduce test dispersion, this 


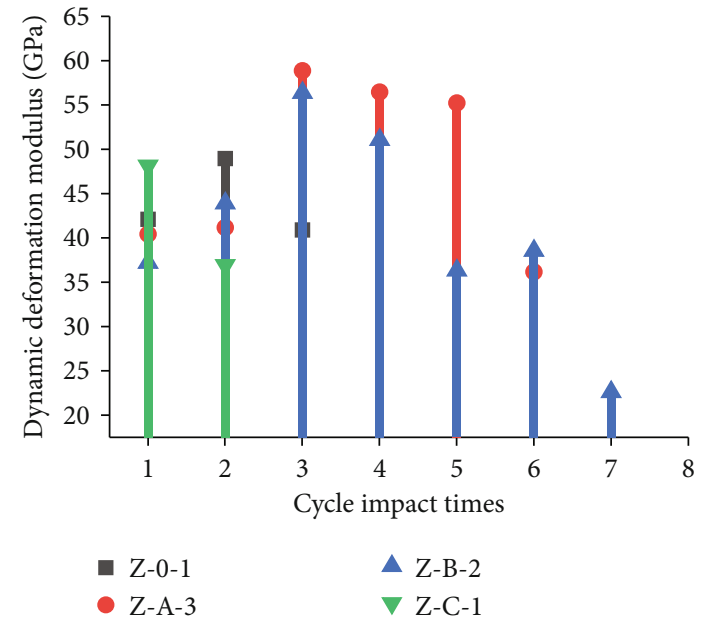

FIGURE 10: Relationship between the dynamic deformation modulus and the number of cycles.

paper adopts the following calculation method proposed by Tang et al. [35]:

$$
\begin{gathered}
E_{1}=\frac{\sigma_{d 50}}{\varepsilon_{d 50}}, \\
E_{2}=\frac{\sigma_{d}-\sigma_{d 50}}{\varepsilon_{d}-\varepsilon_{d 50}}, \\
E_{3}=\tan \alpha, \\
E_{d}=\frac{E_{1}+E_{2}+E_{3}}{3},
\end{gathered}
$$

where $E_{1}$ is the first secant modulus, $E_{2}$ is the second type of secant modulus, $E_{3}$ is the deformation modulus of the loading section, $E_{d}$ is the dynamic deformation modulus, $\sigma_{d 50}$ is $50 \%$ of the peak stress, and $\varepsilon_{d 50}$ is $50 \%$ of the peak stress. The corresponding strain $\sigma_{d}$ is the peak stress, $\varepsilon_{d}$ is the peak strain, $\alpha$ is the angle between the tangent and the axis at $50 \%$ of the peak stress, and $E_{0}$ is the elastic modulus of the material without damage.

In combination with the stress-strain curve in Figure 3, it can be seen that when the axial prestress is low and when the dynamic load initially acts on the rock sample, the internal cracks are further closed, showing that the dynamic deformation modulus increases first and then decreases as the number of cycles increases. When the axial prestress is greater than a certain degree, there are more microcracks in the rock sample, but the overall structure is in a state of stress equilibrium due to axial compression. When the dynamic load is applied, the internal cracks expand rapidly, showing that the dynamic deformation modulus changes. The number of cycles increases at a smaller level. The overall trend of the Z-0-1, Z-A-3, and Z-B-2 dynamic deformation moduli first increases and then decreases, while Z-C- 1 shows a decreasing trend. The increase in the dynamic deformation modulus means that its resistance to deformation is enhanced. The dynamic deformation modulus of the Z-A-3 and Z-B-2 rock samples increases during the first three impacts, indicating that the rock samples are in the crack-closing stage under the impact load, showing a certain hardening effect. The dynamic deformation modulus followed by the cycle number decreases, and the resistance of the rock samples to deformation weakens.

It is further seen from Figure 8 that the maximum deformation modulus of the axial prestress of $42 \%$ of the UCS and $62 \%$ of the UCS is substantially higher than when the axial prestress is not applied. This is because the rock is enhanced when the axial prestress is low. The ability of the sample to resist deformation and the dynamic deformation modulus of the rock sample under impact failure are lower than when axial prestress is not applied. According to the analysis, the rock sample has sufficient internal crack expansion when subjected to multiple impact loads. The deformation modulus is low. When the axial prestress is $83 \%$ of the UCS, the maximum dynamic deformation modulus of the rock sample and the dynamic deformation modulus at failure are lower than those without axial prestress. This is because when the axial prestress is large, the prestress promotes the formation of microcracks in the rock sample, reducing its resistance to deformation.

3.2. Energy Evolution Characteristics of Granite under Dynamic and Static Coupling. Figure 11 shows the relationship between the absorbed energy of the rock sample and the number of cycles under different axial prestressing forces. It can be seen from Figure 11 that the variation law of the absorbed energy varies with different axial prestresses. When axial prestress is not applied, the absorption energy increases with the number of cycles, and the absorption energy is positive, which means that during the cyclic impact process, the rock sample continuously absorbs energy for the initiation and expansion of its internal cracks. In addition, when the axial prestress is $42 \%$ of the UCS, the rock sample increases with the number of cycles, and the energy is converted from the released energy to the absorbed energy. This is because the rock sample has a certain amount of energy stored during the axial prestress, and the first two impact loads, and during the action, the rock samples exhibit energy release, and the released energy decreases as the number of impacts increases. The analysis shows that during the initial impact process, the internal structure of the rock sample is fine-tuned, and the microcracks are continuously closed, resulting in a decrease in the released energy and energy as the number of cycles increases. During the third impact, the rock sample begins to absorb energy, and the absorbed energy is $1.14 \mathrm{~J}$, indicating that the rock sample has a relatively stable internal structure during the third impact, and there is basically no energy dissipation; the rock sample is subjected to the fifth impact. When the load is applied, the energy absorption value is $7.88 \mathrm{~J}$, which is substantially larger than that during the third and fourth impacts, indicating that the crack growth rate and degree of the rock sample increase. When the rock sample is impacted and damaged, the energy absorption value is $28.4 \mathrm{~J}$, which increases sharply, indicating that the specimen has more absorbed energy when it is destroyed, and the degree of damage increases. The axial prestress is $62 \%$ of the UCS, the rock sample releases energy during cyclic impact, and 


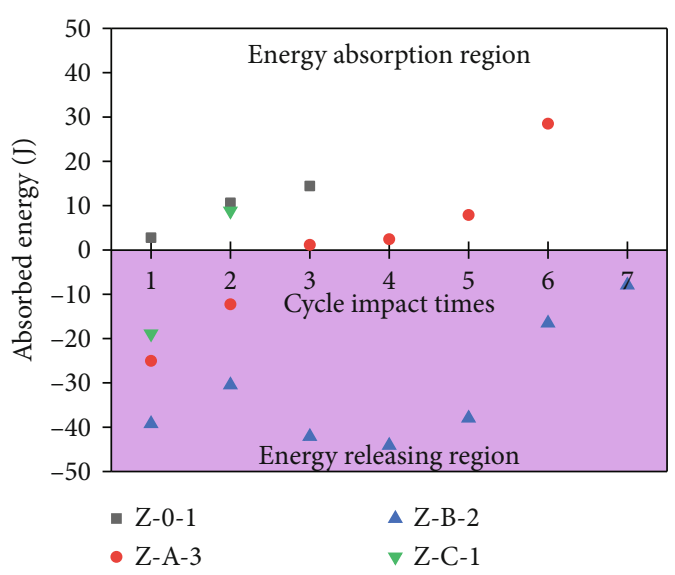

FIGURE 11: Relationship between axial the prestress and absorbed energy.

the overall trend is decreasing. The analysis shows that the rock sample stores substantial strain energy. As the number of cycles accumulates, the internally activated cracks will increase. Due to the release of energy, the internal cracks will continue to expand. During impact failure, the residual elastic energy inside the rock sample will be greater than the fracture. The surface requires energy, and under the action of dynamic loading, it triggers the release of its energy, which eventually leads to a "rock burst" in the rock sample. The axial prestress is $83 \%$ of the UCS, and more cracks have been induced inside the rock sample, resulting in less stored energy. During the first impact, the energy is released internally, causing more cracks to activate and propagate inside, and a certain macroscopic damage occurs on the surface. In this state, because the internal energy storage is low, the rock sample is under the impact of the impact load. "Rock bursts" are less likely to occur in this stage, so the specimens show absorbed energy when they finally fail.

\subsection{Dynamic and Static Coupling Failure Modes of Granite.} Understanding the rock failure mode is of practical engineering significance for underground mining processes and the prevention of hazards such as rock bursts. Figure 12 shows the fracture process of specimens under different axial prestressing forces under the same air pressure impact, and Figure 11 shows the corresponding failure mode.

When the axial prestress is not applied, under the impact of the dynamic load cycle of the sample, the reflected wave and the transmitted wave in the rock sample cannot be transmitted to the two ends of the sample in time, resulting in a superposition at a certain position inside the rock sample and a greater tensile wave. The existence of holes further weakens the tensile strength of the rock sample so that microcracks in other positions of the rock sample will not be able to propagate and penetrate in the future, and a through tensile crack perpendicular to the loading direction appears at a certain position, triggering the damage of the rock sample. The spalling damage leads to a larger size of the final damage and less damage. Figure 12(a) shows a diagram of the failure process of the rock sample without axial prestress failure. At $1104 \mu \mathrm{s}$, cracks perpendicular to the loading direction begin to appear in the centre of the rock sample, and debris appears at the incident end of the rock sample, which eventually leads to spalling failure of the rock sample at $3335 \mu$ s.

When the rock sample is under axial prestress, a potential compression-shear surface is formed inside. During the initial cyclic impact process, because the impact strength is lower than the maximum compressive strength of the prestress, the rock sample does not undergo macroscopic damage. As the cyclic impact accumulates to a certain degree, the maximum strength of the prestress is continuously weakened. When the impact strength of the prestress is higher than the minimum strength to which the prestress is subjected, the rock sample will fail.

When the axial prestressing force is $42 \%$ of the UCS and $62 \%$ of the UCS, the axial prestress and dynamic load act simultaneously, resulting in mixed tensile-shear failure. When the axial prestress is $42 \%$ of the UCS, Figure 12(b) shows that when the transmitting end of the rock sample is at $276 \mu \mathrm{s}$, compression cracks begin to appear, and at $345 \mu$ s, tensile cracks appear at the ends while the end face of the rock sample is sheared and fragments began to peel off. At $598 \mu \mathrm{s}$, a tensile crack appears on the surface of the rock sample. When the axial prestress is $62 \%$ of the UCS, Figure 12(c) shows that the rock sample begins to undergo compression-shear failure when the rock sample is broken. At $161 \mu \mathrm{s}$, compression shear cracks appear from the entrance side of the specimen. At $368 \mu \mathrm{s}$, the fragments on the compression shear surface begin to eject from the side and make a loud noise. This phenomenon is similar to a "rock burst" in rock engineering.

When the axial prestressing force is $83 \%$ of the UCS, the axial prestress plays a major role, and shear tensile mixed failure occurs. It can be observed from Figure 12(d) that the rock sample cracks at $253 \mu \mathrm{s}$, and at $414 \mu \mathrm{s}$, chipping occurs on the side of the rock. The analysis shows that the prestress is $83 \%$ of the UCS, a more obvious compression zone is formed at the end of the sample, and the internal cracks parallel to the loading direction expand to the inside [21], forming a potential "shear failure surface", resulting in more obvious compression on both sides. The shear rupture surface, when impact load is applied, further promotes this formation trend and triggers rock chipping on the side of the rock.

Sliding loads act on different axial prestress failure modes. Figure 13 shows that as the axial prestress increases, the failure block size of the rock samples does not decrease substantially. The main reason for this behaviour is that in this study, granite was not severely damaged. When the prestress is in the stage of stable crack growth, which is lower than the crack damage stress (70\% of the UCS) [14], under cyclic impact loading, the rock sample will undergo certain fatigue damage, and its internal microcracks gradually change from the initial compaction stage. The crack propagation stage is transitional, and the crack propagation speed is slow. When the final impact is broken, the crack is full, and the fragmentation is small. When the prestress is higher than the crack damage stress, the number of cyclic impacts of the rock sample is lower, which indicates that the main crack is propagating faster, and the internal microcracks have time 


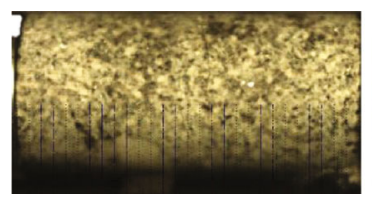

$1104 \mu \mathrm{s}$

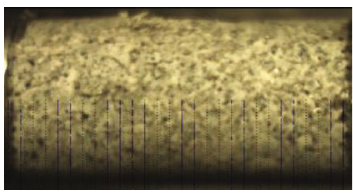

$276 \mu \mathrm{s}$

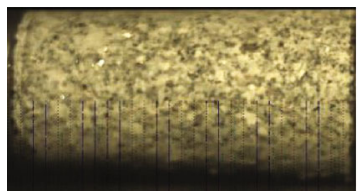

$161 \mu \mathrm{s}$

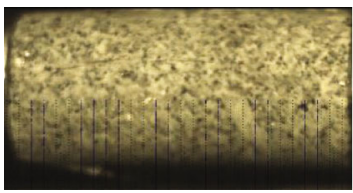

$253 \mu \mathrm{s}$

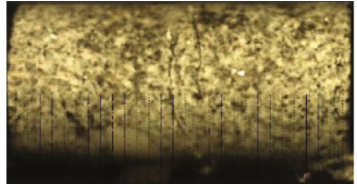

$2070 \mu \mathrm{s}$

(a) Z-0-1

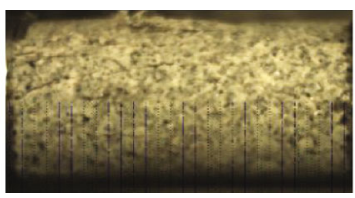

$345 \mu \mathrm{s}$

(b) Z-A-3

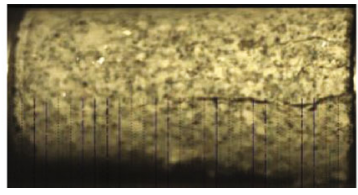

$230 \mu \mathrm{s}$

(c) Z-B-2

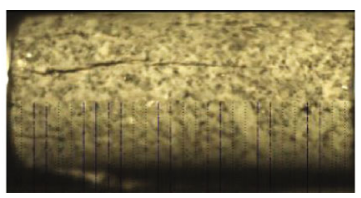

$414 \mu \mathrm{s}$

(d) Z-C-1

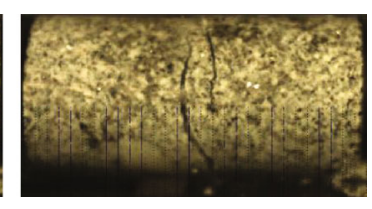

$3335 \mu \mathrm{s}$

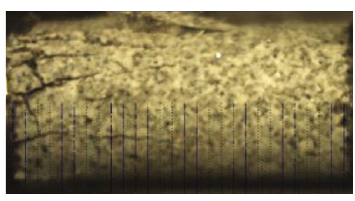

$598 \mu \mathrm{s}$

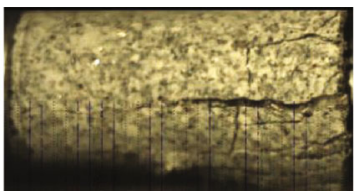

$368 \mu \mathrm{s}$

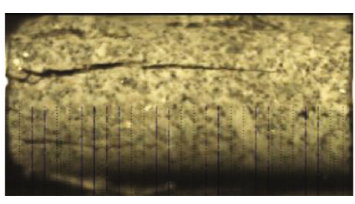

$713 \mu \mathrm{s}$

Figure 12: Failure process diagram of different axial prestress loads.

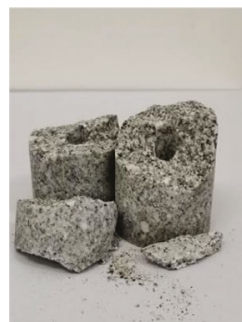

Z-0-1

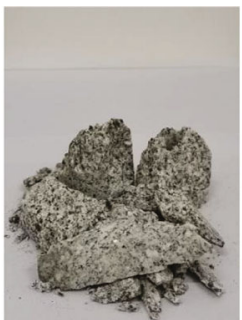

Z-A-3

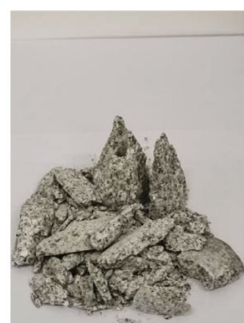

Z-B-2

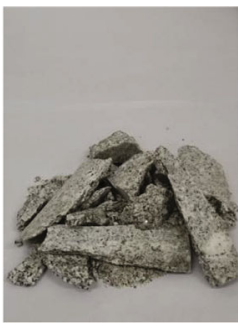

Z-C-1

FIgURE 13: Different axial prestress failure modes.

to grow. The main crack expands and penetrates, resulting in larger fragments during failure.

\subsection{Damage Characteristics Analysis}

3.4.1. Selection and Establishment of the Dynamic Rock Damage Model. At present, the commonly used damage variables are defined as the elastic modulus, maximum strain, and ultrasonic wave speed. The ultrasonic wave speed is widely used because it is easy to operate and can effectively reflect the crack propagation trend in rock, but it has a cycle under a certain axial prestress. Impact tests limit the application of this method. For this reason, Jin Jiefang established a method based on the one-dimensional stress wave theory. Under the same cross-sectional area of the test specimen and the elastic rod, the wave impedance is used to define the damage variable for the first time, as shown in Equation (4). The elastic modulus, energy dissipation, and maximum strain are not suitable for defining the damage variables of rock during cyclic impact [36]. In this paper, the vertical centre hole is prefabricated in the centre of the sample. Therefore, Equation (4) cannot be directly applied to this test. Assuming that the discontinuous contact surface between the rock sample and the elastic rod is regarded as the contact surface between two elastic halfspaces with displacement discontinuity, the propagation of the stress wave on the displacement discontinuity surface 
can be transformed into a boundary value problem for solving the wave equation [32], as shown in Figure 14.

$$
D=1-\left(\frac{\overline{\rho C}}{\rho C}\right)^{1.6}
$$

where $D$ is the damage variable, $(\overline{\rho C})$ is the wave impedance at a certain impact, and $\rho C$ is the initial wave impedance of the rock.

As shown in the figure, based on the one-dimensional wave theory, when the stress wave propagates from incident rod $a$ to test piece $b$, its wave impedance changes from $\mathrm{m}_{\mathrm{a}}$ to $\mathrm{m}_{\mathrm{b}}$. According to the one-dimensional stress wave theory, the interface has a continuous force and velocity on $\mathrm{O}_{1} \mathrm{O}_{2}$ with the following available conditions:

$$
\begin{gathered}
\sigma_{R}\left(t_{i}\right)=\lambda \sigma_{I}\left(t_{i}\right), \\
\sigma_{T}\left(t_{i}\right)=(1+\lambda)(1-\lambda), \\
m_{a}=\rho_{a} C_{a} A_{a}, \\
m_{b}=\rho_{b} C_{b} A_{b}, \\
\lambda=\frac{m_{a}-m_{b}}{m_{a}+m_{b}} .
\end{gathered}
$$

In the same way, $\sigma_{T}^{\prime}\left(t_{i}\right)$ inside the rock enters the transmission rod at interface $\mathrm{O}_{3} \mathrm{O}_{4}$ to generate a transmitted wave:

$$
\sigma_{T}\left(t_{i}\right)=(1+\lambda)(1-\lambda) \sigma_{I}\left(t_{i}\right)
$$

The relationship between the transmitted wave and the incident wave at any time can be written as follows:

$$
\xi\left(t_{i}\right)=\frac{\sigma_{T}\left(t_{i}\right)}{\sigma_{I}\left(t_{i}\right)}=(1+\lambda)(1-\lambda) .
$$

If $\mathrm{m}_{\mathrm{a}}$ and $\mathrm{m}_{\mathrm{b}}$ are known, Equation (11) can be rearranged, and Equations (7), (8), and (9) can be simultaneously used to obtain the actual wave impedance of the rock specimen at a certain moment during the $i$ time impact:

$$
\rho_{i} C_{i}=\frac{A_{b}\left(2-\xi\left(t_{i}\right)-2 \sqrt{1-\xi\left(t_{i}\right)}\right)}{A_{a} \xi\left(t_{i}\right)} \rho_{a} C_{a} .
$$

By taking Equation (12) into Equation (4), the expression of the damage degree of the rock is as follows:

$$
D=1-\left(\frac{A_{b}\left(2-\xi\left(t_{i}\right)-2 \sqrt{1-\xi\left(t_{i}\right)}\right) \rho_{a} C_{a}}{A_{a} \xi\left(t_{i}\right) \rho C}\right)^{1.6}
$$

where $\sigma_{I}, \sigma_{R}, \sigma_{T}$, and $\sigma_{T}^{\prime}$ are the incident wave, reflected wave, transmitted wave, and transmitted wave in the specimen, respectively; $A_{a}$ and $A_{b}$ are the cross-sectional areas of the elastic rod and the rock sample, respectively; $\rho_{a}$ and $C_{a}$, and $\rho_{b}$ and $C_{\mathrm{b}}$ are the density and P-wave velocity of the elas- tic rod and rock sample, respectively; $\lambda$ is the reflection coefficient of the wave entering the specimen from the elastic rod; and $i$ is the $i$ th time impact order.

The above inference formula assumes that the stress wave in the rock specimen generates a transreflective reflection. After the incident wave propagates into the specimen for a period of time, multiple transmissive reflections occur in the specimen at each instant. From the research in [36], it is evident that when $t \leq\left(2 L_{b} / C_{b}\right)$, the reflected and transmitted waves obtained in the test are not affected by multiple transmissions and reflections. Figure 15 shows a trend chart of the change in the wave impedance when a certain specimen is impacted. The impedance of section $\mathrm{AB}$ basically remains unchanged. To produce comparable results, a certain time in section $A B$ is selected as the reference point for each cycle of the test specimen.

3.4.2. Influence of the Axial Prestress on the Damage. Figure 16 shows the change in the damage degree and impact number of the rock samples under different axial prestressing forces. It can be seen from the figure that the rock samples show different damage evolution trends with the increase in the number of cycles under different prestresses. The initial damage of Z-0-1 is lower than that of the other rock samples, and the initial damage of Z-A-3, Z-B-2, and Z-C-1 increases with the increase in the axial prestress. The rock samples have different degrees of damage when the prestress is $42 \%$ of the UCS, $62 \%$ of the UCS, and $83 \%$ of the UCS. Z-C-1 has a large number of microcracks because the axial prestress is higher than the crack damage stress, resulting in a substantial reduction in the number of cycles of rock samples subjected to cyclic impact. The cumulative growth rate of the damage of Z-0-1 continues to increase, with growth rates of $60 \%$ and $150 \%$, respectively. During the initial cyclic impact process, Z-A-3 is dominated by compaction, resulting in the reduction in the first three damage levels, and then with the increase in the number of cycles, the cumulative damage growth rate of the rock sample increases with the acceleration of the internal crack growth. Z-B-2 increases the cumulative damage rate during the first four cycles of slow impact, with a range of $0.24-0.25$. From the establishment of the dynamic damage model, it can be seen that the damage $\mathrm{D}$ is a function of the strain [37], which is consistent with the maximum strain in the previous analysis. Since the rock sample belongs to the fatigue damage stage at this stage, the amplitude of the strain change is small, which means that during this impact process, the damage to the rock sample is small and can almost be ignored. This shows that the cumulative damage growth of the rock sample during the first four impacts is slow, and the damage accumulation during the subsequent cyclic impact process increases with the increase in the maximum strain.

\section{Surrounding Rock Engineering Applications of Roadways under Different Prestresses}

The in situ stress and dynamic load affect the safety and stability of the roadway. Among them, the magnitude of the 


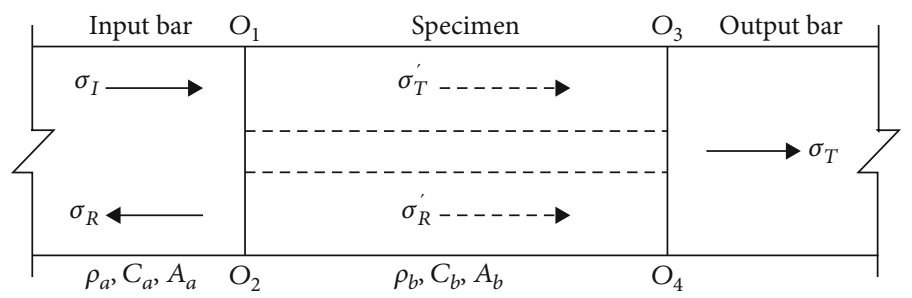

FIgURE 14: Transmission and reflection of a one-dimensional compressional wave in a rock sample.

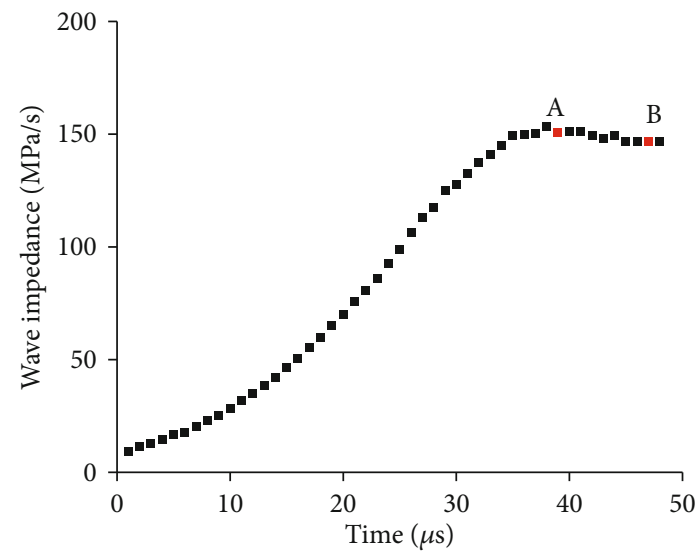

Figure 15: Trend chart of wave impedance over time.

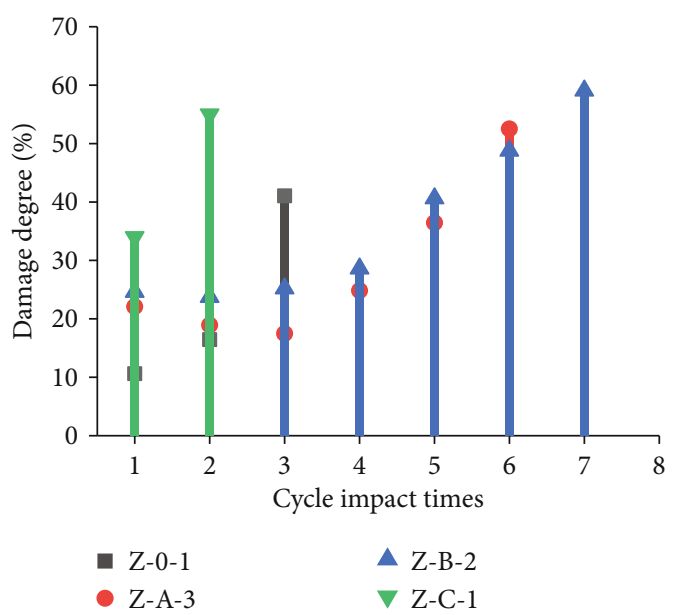

FIGURE 16: Relationship between different axial prestresses and damage levels.

ground stress (prestress) determines the strength and stiffness of the surrounding rock of the roadway. Figure 17 shows the maximum peak stress and dynamic deformation modulus, which indirectly reflect the rock mass stiffness. The test results show that when the prestress is higher than the crack initiation stress (30\% of the UCS), the dynamic strength and stiffness are reduced and increased, respectively, compared with the absence of axial prestress, which indicates that the in situ stress improves the "toughness" of the surrounding rock. Under the same dynamic load disturbance action, the ability to resist the instability and damage of the surrounding rock of the roadway is enhanced. When the axial prestress is higher than the crack damage stress ( $70 \%$ of the UCS), the strength and stiffness are reduced compared with the axial prestress. It can be concluded that under high prestress conditions, the dynamic load disturbance is extremely detrimental to the stability of the surrounding rock of the roadway, and it is more likely to cause instability.

The failure type and energy evolution law of the surrounding rock of the roadway are also important features that reveal the failure mechanism of the surrounding rock. For tunnels with shallow depths, it can be considered that there is no static stress. If the surrounding rock of the roadway is to be destabilized and destroyed, it is necessary to absorb the external energy, and the failure of the surrounding rock of the roadway is usually caused by the tensile spalling damage caused by the superposition of the stress waves due to the dynamic load at a certain position of the roadway surrounding rock. For the surrounding rock of the roadway where the prestress is in the stage of stable expansion of the crack, as the depth increases, a certain degree of shear surface is formed inside, and the stored energy increases; when the external load is disturbed, the surrounding rock of the roadway is transformed from absorbed energy to released energy when the surrounding rock is destroyed, which results in a greater probability of triggering a rock burst. For the prestressed roadway surrounding rock in the unstable stage of crack expansion, which is higher than the crack damage stress, the structure of the roadway surrounding rock is almost in an unstable state, there are many microcracks inside, the rock density is very low, and the stored energy is relatively small. When the load is disturbed, the internal absorbed energy is greater than the released energy. In this case, rock burst does not easily occur, and the roadway is easily induced to collapse and fall off.

\section{Conclusion}

(1) The axial prestress has a certain effect on the dynamic strength and stiffness of granite: the axial prestress is in the stage of stable crack propagation, and its dynamic strength is lower than that of the pure dynamic compressive strength, but its stiffness increases. The axial prestress is in the unstable stage of crack propagation, showing its weakest dynamic strength and stiffness

(2) During the cyclic impact failure process of granite, the granite mainly undergoes a transition from the compaction stage to the fatigue damage stage to the failure stage. With the increase in the prestressed axial pressure, the compaction stage and the fatigue 


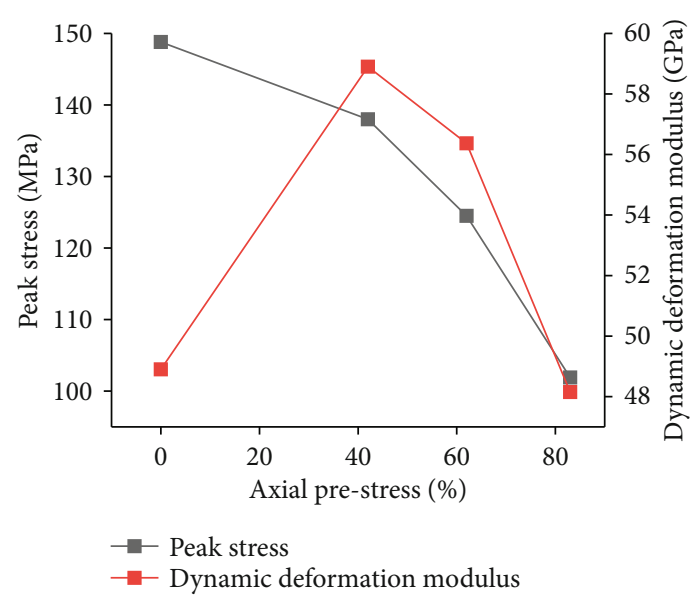

FIGURE 17: Relationship between the dynamic deformation modulus, peak stress, and axial prestress.

damage stage continue to weaken. When the axial prestress is $42 \%$ of the UCS, the rock sample shows the compaction stage-fatigue damage stage-failure stage trend; when the axial prestress is $62 \%$ of the UCS, the rock sample compaction stage weakens, showing the fatigue damage stage-failure stage trend; and when the axial prestress is $83 \%$ of the UCS, the rock sample only shows the failure stage

(3) The existence of static stress is a necessary condition for "rock burst" to occur. Granite under different axial prestresses, the energy dissipation of rocks varies with the number of impacts. In general, when the axial prestress and impact load are at a certain value, the probability of "rock burst" is large

(4) The failure mode of granite under different axial prestresses is different. When the axial prestress is 0 , spalling tensile failure occurs. As the axial prestress increases, mixed tensile-shear failure occurs. This is due to the effect of axial prestressing, and different levels of shear planes are formed inside, which limits the initiation of transverse cracks

(5) Based on the one-dimensional stress wave theory, the method of defining the rock damage degree by wave impedance is further studied. When the rock sample is in the compaction stage and the fatigue damage stage, the damage of the specimen is small, and the damage reduction phenomenon occurs

\section{Data Availability}

The data used to support the findings of this study are available from the corresponding author upon request.

\section{Conflicts of Interest}

The authors declare that they have no known competing financial interests or personal relationships that could have appeared to influence the work reported in this paper.

\section{Authors' Contributions}

Bing Dai is responsible for the methodology and conceptualization. Yongming Xue is responsible for the investigation and data curation. Lei Zhang is responsible for the writing of the original draft, validation, and visualization. Ying Chen is responsible for the resources and writing of the review and editing. Zhijun Zhang is responsible for the supervision.

\section{Acknowledgments}

This study is conducted under the joint grant of the National Natural Science Foundation of China (Nos. 51804163 and 51974163) and the China Postdoctoral Science Foundation (2018M642678), and it is supported by the Hunan Provincial Innovation Foundation for Postgraduate (CX20200920).

\section{References}

[1] X. B. Li, F. Q. Gong, and S. F. Wang, "Coupled static-dynamic loading mechanical mechanism and dynamic criterion of rock burst in deep hard rock mines," Chinese Journal of Rock Mechanics and Engineering, vol. 38, no. 4, pp. 708-723, 2019.

[2] P. X. Li, X. T. Feng, G. L. Feng, Y. X. Xiao, and B. R. Chen, "Rockburst and microseismic characteristics around lithological interfaces under different excavation directions in deep tunnels," Engineering Geology, vol. 260, p. 105209, 2019.

[3] L. Hu, X. T. Feng, Y. X. Xiao et al., "Effects of structural planes on rockburst position with respect to tunnel cross-sections: a case study involving a railway tunnel in China," Bulletin of Engineering Geology and the Environment, vol. 79, no. 2, pp. 1061-1081, 2020.

[4] Z. Song, H. Konietzky, and M. Herbst, "Bonded-particle model-based simulation of artificial rock subjected to cyclic loading," Acta Geotechnica, vol. 14, no. 4, pp. 955-971, 2019.

[5] Z. Song, H. Konietzky, and M. Herbst, "Three-dimensional particle model based numerical simulation on multi-level compressive cyclic loading of concrete," Construction and Building Materials, vol. 225, pp. 661-677, 2019.

[6] F.-q. Gong, X.-f. Si, X.-b. Li, and S.-y. Wang, "Experimental investigation of strain Rockburst in circular caverns under deep three-dimensional high-stress conditions," Rock Mechanics and Rock Engineering, vol. 52, no. 5, pp. 1459$1474,2019$.

[7] X. B. Li, C. J. Li, W. Z. Cao, and M. Tao, "Dynamic stress concentration and energy evolution of deep-buried tunnels under blasting loads," International Journal of Rock Mechanics and Mining Sciences, vol. 104, pp. 131-146, 2018.

[8] Z. Song, W. Wei, and J. Zhang, "Numerical investigation of effect of particle shape on isolated extracted zone (IEZ) in block caving," Arabian Journal of Geosciences, vol. 11, no. 12, 2018.

[9] B. Y. Jiang, S. T. Gu, L. G. Wang, G. C. Zhang, and W. S. Li, "Strainburst process of marble in tunnel-excavation-induced stress path considering intermediate principal stress," Journal of Central South University, vol. 26, no. 4, pp. 984-999, 2019.

[10] Z. L. Li, X. Q. He, L. M. Dou, and G. F. Wang, "Rockburst occurrences and microseismicity in a longwall panel experiencing frequent rockbursts," Geosciences Journal, vol. 22, no. 4, pp. 623-639, 2018. 
[11] B. Dai and Y. Chen, "A novel approach for predicting the height of the water-flow fracture zone in undersea safety mining," Remote Sensing, vol. 12, no. 3, p. 358, 2020.

[12] K. Gao, S. N. Li, R. Han et al., "Study on the propagation law of gas explosion in the space based on the goaf characteristic of coal mine," Safety Science, vol. 127, article 104693, 2020.

[13] Z. Song and H. Konietzky, "A particle-based numerical investigation on longwall top coal caving mining," Arabian Journal of Geosciences, vol. 12, no. 18, 2019.

[14] Z. Zhou, X. Cai, X. Li, W. Cao, and X. du, "Dynamic response and energy evolution of sandstone under coupled staticdynamic compression: insights from experimental study into deep rock engineering applications," Rock Mechanics and Rock Engineering, vol. 53, no. 3, pp. 1305-1331, 2020.

[15] X. Cai, Z. L. Zhou, and X. du, "Water-induced variations in dynamic behavior and failure characteristics of sandstone subjected to simulated geo-stress," International Journal of Rock Mechanics and Mining Sciences, vol. 130, article 104339, 2020.

[16] X. Cai, Z. L. Zhou, H. Zang, and Z. Song, "Water saturation effects on dynamic behavior and microstructure damage of sandstone: phenomena and mechanisms," Engineering Geology, vol. 276, article 105760, 2020.

[17] X. Cai, Z. L. Zhou, L. H. Tan, H. Zang, and Z. Song, "Fracture behavior and damage mechanisms of sandstone subjected to wetting-drying cycles," Engineering Fracture Mechanics, vol. 234, article 107109, 2020.

[18] X. B. Li, Z. L. Zhou, and Z. Y. Ye, "Study of rock mechanical characteristics under coupled static and dynamic loads," Chinese Journal of Rock Mechanics and Engineering, vol. 7, pp. 1387-1395, 2008.

[19] T. Wang, Z. P. Song, and J. Y. Yang, "Dynamic response characteristics of weathered red sandstone under cyclic impact," Chinese Journal of Rock Mechanics and Engineering, vol. 38, no. S1, pp. 2772-2778, 2019.

[20] F. Q. Gong, X. B. Li, and X. L. Liu, "Experimental study on dynamic characteristics of sandstone under one-dimensional coupled static and dynamic loads," Chinese Journal of Rock Mechanics and Engineering, vol. 29, no. 10, pp. 2076-2085, 2010.

[21] F. Q. Gong, Experimental study of rock mechanical properties under l coupled static-dynamic loads and dynamic strength criterion, Central South University, 2010.

[22] X. B. Li, F. Q. Gong, and K. Gao, "Test study of impact failure of rock subjected to one-dimensional coupled static and dynamic loads," Chinese Journal of Rock Mechanics and Engineering, vol. 29, no. 2, pp. 251-260, 2010.

[23] F. Wang, M. Wang, Z. M. Zhu, Q. Hao, Y. Peng, and W. Xuya, "Study on evolution law of rock crack dynamic propagation in complete process under impact loading," Chinese Journal of Rock Mechanics and Engineering, vol. 38, no. 6, pp. 11391148, 2019.

[24] B. Dai, Y. Chen, G. Y. Zhao, W. Liang, and H. Wu, "A numerical study on the crack development behavior of rock-like material containing two intersecting flaws," Mathematics, vol. 7, no. 12, p. 1223, 2019.

[25] D. Li, P. Xiao, Z. Han, and Q. Zhu, "Mechanical and failure properties of rocks with a cavity under coupled static and dynamic loads," Engineering Fracture Mechanics, vol. 225, article 106195, 2020.

[26] D. Li, T. Cheng, T. Zhou, and X. Li, "Experimental study of the dynamic strength and fracturing characteristics of marble specimens with a single under impact loading," Chinese Journal of Rock Mechanics and Engineering, vol. 34, no. 2, pp. 249-260, 2015.

[27] Y. Li, J. Peng, F. Zhang, and Z. Qiu, "Cracking behavior and mechanism of sandstone containing a pre-cut hole under combined static and dynamic loading," Engineering Geology, vol. 213, pp. 64-73, 2016.

[28] Q. Z. Wang, B. B. Wu, F. Liu, K. W. Xia, and W. Wang, "Dynamic failure of manufactured similar rock plate containing a single fissure," Chinese Journal of Rock Mechanics and Engineering, vol. 37, no. 17, pp. 2489-2497, 2018.

[29] X. B. Li, L. Weng, X. Xie, and Q. H. Wu, "Study on the degradation of hard rock with a pre-existing opening under staticdynamic loadings using nuclear magnetic resonance technique," Chinese Journal of Rock Mechanics and Engineering, vol. 34, no. 10, pp. 1985-1993, 2015.

[30] J. Jin, X. Li, and Z. Yin, "Effects of axial pressure and number of cyclic impacts on dynamic mechanical characteristics of sandstone," Journal of China Coal Society, vol. 37, no. 6, pp. 923930, 2012.

[31] H. J. Su, H. W. Jing, C. Wang, and B. Meng, "Strength attenuation law of damaged rock samples and its structure effect," Applied Mechanics and Materials, vol. 353-356, pp. 602-607, 2013.

[32] X. B. Li, Rock Dynamics Foundation and Application, Science Press, Beijing, 2014.

[33] Z. L. Wang, H. Yang, and N. C. Tian, "Mechanical property and damage evolution mechanism of granite under uniaxial cyclic impact," Journal of Harbin Institute of Technology, vol. 52, no. 2, pp. 1-9, 2020.

[34] J. F. Jin, Study on Rock Mechanical Properties under Coupled Static-Cyclic Impact Loadings, Central South University, 2012.

[35] L. Z. Tang, T. Liu, C. Wang et al., "Study on dynamic deformation modulus of rock under confining pressure unloading and dynamic loading," Explosion and Shock Waves, vol. 38, no. 6, pp. 1353-1363, 2018.

[36] J. F. Jin, X. B. Li, Z. Q. Yin, and Y. Zou, “A method for defining rock damage variable by wave impedance under cyclic impact loadings," Rock and Soil Mechanics, vol. 32, no. 5, pp. 13851393, 2011.

[37] J. J. Zhu, X. B. Li, F. Q. Gong, and S. M. Wang, "Dynamic characteristics and damage model for rock under uniaxial cyclic impact compressive loads," Chinese Journal of Geotechnical Engineering, vol. 35, no. 3, pp. 531-539, 2013. 